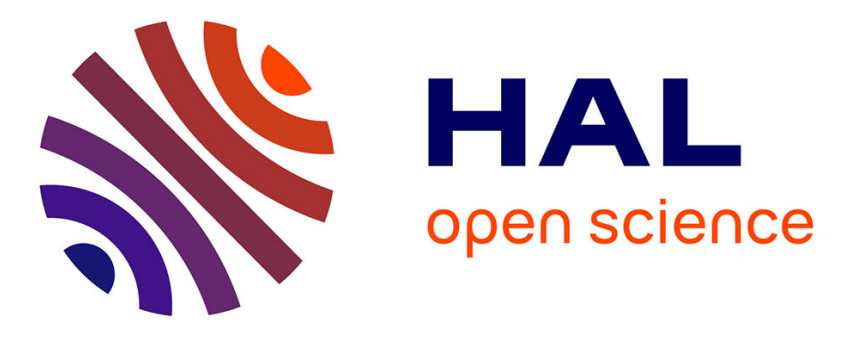

\title{
Engaging Citizens in Policy Issues: Multidimensional Approach, Evidence and Lessons Learned
}

Elena Sánchez-Nielsen, Deirdre Lee, Eleni Panopoulou, Simon Delakorda, Gyula Takács

\section{- To cite this version:}

Elena Sánchez-Nielsen, Deirdre Lee, Eleni Panopoulou, Simon Delakorda, Gyula Takács. Engaging Citizens in Policy Issues: Multidimensional Approach, Evidence and Lessons Learned. 6th International Conference on Electronic Participation (ePart), Sep 2014, Dublin, Ireland. pp.102-113, 10.1007/978-3-662-44914-1_9. hal-01396964

\section{HAL Id: hal-01396964 \\ https://inria.hal.science/hal-01396964}

Submitted on 15 Nov 2016

HAL is a multi-disciplinary open access archive for the deposit and dissemination of scientific research documents, whether they are published or not. The documents may come from teaching and research institutions in France or abroad, or from public or private research centers.
L'archive ouverte pluridisciplinaire HAL, est destinée au dépôt et à la diffusion de documents scientifiques de niveau recherche, publiés ou non, émanant des établissements d'enseignement et de recherche français ou étrangers, des laboratoires publics ou privés.

\section{(c)(1)}

Distributed under a Creative Commons Attribution| 4.0 International License 


\title{
Engaging Citizens in Policy Issues: Multidimensional Approach, Evidence and Lessons Learned
}

\author{
${ }^{1}$ Elena Sánchez-Nielsen, ${ }^{2}$ Deirdre Lee, ${ }^{3}$ Eleni Panopoulou, ${ }^{4}$ Simon Delakorda and \\ ${ }^{5}$ Gyula Takáks \\ ${ }^{1}$ Departmento de Ingeniería Informática. Universidad de La Laguna, S/C de Tenerife, Spain. \\ ${ }^{2}$ DERI, NUI Galway, IDA Business Park, Lower Dangan, Ireland. \\ ${ }^{3}$ Centre for R\&T Hellas (CERTH) and Greek R\&T Network (GRNET), Greece. \\ ${ }^{4}$ Institute for Electronic Participation (INePA), Ljubljana, Slovenia, \\ ${ }^{5}$ NISZ National Infocommunications Service Compay Ltd., Hungary \\ 1enielsen@ull.edu.es, ${ }^{2}$ Deirdre.Lee@deri.org, ${ }^{3}$ epanopou@iti.gr, \\ ${ }^{4}$ Simon.delakorda@inepa.si, ${ }^{5}$ takacs.gyulapeter@nisz.hu
}

\begin{abstract}
E-participation offers individuals, groups and non-governmental institutions the opportunity to learn about and discuss policy so they can make more informed choices in their personal lives as citizens, and to contribute to policy drafting as an instrument to strengthen the quality of decision-makers' actions. Although a growing body of literature has been devoted to the main benefits and opportunities that ICT can offer in e-participation, little is known about the driving forces that foster public participation and citizens' active engagement. This paper describes a multidimensional engagement approach, supported by an inform-consult-empower framework, to strengthen the foundation for participatory policy-making. This approach addresses the following key issues: public participation, public involvement, deliberative democracy, and collaborative governance. This approach has been designed, investigated and applied in the context of the European Commission project "Puzzled by Policy: Helping you be part of the EU". The findings suggest that the use of a multidimensional engagement approach with a user-centric focus from the outset is essential to foster social participation, raise trust between citizens and government, and promote constructive narratives to put into the policy-making process.
\end{abstract}

\section{Introduction}

Active citizen engagement and clear impact are hallmarks of a successful eparticipation initiative. In recent years, the EU and its Member States have mounted a concerted effort to find workable mechanisms to enhance e-participation under the Fifth, Sixth and Seventh Framework Programmes for Research. This was continued under the CIP ICT Policy Support Programme in 2009, which focused on empowering and involving citizens in transparent decision making [1]. Many of these e-participation projects have not been as successful as initially anticipated [2]. This is somewhat surprising, as many studies have shown that there are many benefits of 
citizen participation, including tapping into local knowledge and innovation, reducing or avoiding conflict, increasing social inclusion or cohesion, mobilising new resources including voluntary labour, reducing transaction costs, and generating trust and social capital [3]. In this context, one of the main lessons identified by the 2009 European e-participation Summary Report is that more focus is needed on better eparticipation project design [4]. The key dimensions to characterize e-participation initiatives have been described by Macintosh [5] and the OECD Report [6]. Recently, the importance of including social media political discussions between citizens in eparticipation platforms has also been outlined [7]. Although a growing body of literature has been devoted to the main benefits and opportunities that ICT can offer in e-participation, little is known about the driving forces that foster public participation and citizens' active participation. Therefore, a lot of lessons still have to be learned about how to use ICT effectively for public engagement in e-participation initiatives.

The aim of this paper is to argue that citizens cannot be viewed just as a digital audience to politics or merely as virtual customers of government. Instead, citizens should be treated as a vital resource for effective problem solving and community building to offer a plausible solution to policy-making challenges. With this goal, an inform-consult-empower theoretical framework developed in earlier work $[8,12]$ is used to identify the core dimensions we propose are vital to overcome the challenges of engagement from the perspective of an e-participation initiative.

The remainder of this paper is organized as follows. Section 2 reviews the state of practice of citizen engagement. Section 3 outlines the inform-consult-empower theoretical framework that is used to support the proposed multidimensional engagement approach and the Puzzled by Policy platform that is used to test this approach. Section 4 describes the rationale and key dimensions of the engagement approach. Section 5 provides the evidence to date with the use of this engagement approach in the Puzzled by Policy project. Section 6 gives lessons learned of interest to anyone who is trying to use ICT in order to support online democratic engagement. Finally, section 7 points out the main conclusions.

\section{State of Practice of Citizen Engagement}

Democracies around the world face challenges related to citizen engagement with political institutions. Discussions theoretically allow citizens to air their disagreements, create opportunities to reconsider initial approaches, and foster understanding of alternative perspective and viewpoints [9]. In recent years, traditional approaches to connect citizens with decision-makers and policy-making have evolved. There has been a shift from citizens as passive consumers to active participants in the policy-making process. This adjustment towards viewing citizen engagement as fundamental knowledge-building contributes to the transparency, legitimacy and fairness of policy development. However, simply opening up a policymaking process to citizens is not sufficient to ensure public engagement. Currently, there are diverse reasons for citizens and decision makers to not become involved in the policy making process. On the citizen side, two broad groups can be identified 
[10]: audiences who are 'willing but unable' to participate due to a variety of reasons such as cultural or language barriers, geographical distance, disability, or socioeconomic status reflecting in digital inequalities (divide), and audiences who are 'able but unwilling' to participate, perhaps because they are not very interested in politics, do not have the time, or do not trust government to make good use of their input. In order to ensure the engagement of these types of hard-to-reach audiences, as well as the general public, it is vital to design a holistic public engagement approach. While the use of ICT approaches can certainly help with accessibility, transparency, dissemination and analysis, they should not be viewed as a complete solution.

To date, a lot of common approaches to public engagement in decision processes reflect a mechanistic, top-down orientation that does not maximize the benefits of public engagement $[15,16]$. Policy-makers with a particular goal or domain in mind initiate a discussion and try and encourage people to contribute. This kind of participation is important as those with the power to implement the results of the discussion are directly involved. The challenges of such initiatives are sometimes seen by the public as fake engagements, with no real potential for impact. Or the impact of the discussion is diluted in the political process and its effects are not clear for those participating. As a consequence, bottom-up approaches and grassroots movements have alternatively risen in recent years. As an organic development of ideas, this approach to participation can introduce topics onto the agenda that the policy-makers may not have originally been interested in. On the other side, bottomup movements may find it difficult to have any impact until at some stage the policymakers pay attention and engage in discussions. Therefore, these types of initiatives need a critical mass behind it as well as organisational capacities.

\section{Puzzled by Policy Concept}

Puzzled by Policy aims to reduce the complexity of decision making within the EU and reconnect citizens with decision makers and policy making in an engaging way. Puzzled by Policy is modelled around an inform-consult-empower framework designed in previous work $[8,12]$ which offers all stakeholders the opportunity to participate in an appropriate and achievable setting based on the stage of the policy process they are. The aim is to offer different levels of participation that is realistic and achievable. Inform-consult-empower framework recognises that citizen engagement is an iterative process; initially people are more likely to want to simply find out information about policies than to discuss them; subsequently, people are more inclined to discuss policy topics than to propose new ideas or drive policy change. The inform-consult-empower framework is structured in terms of Kingdon's Multiple Stream Model [11] and the Conference of International NGOs of the Council of Europe's Policy Cycle Model [17]. Both models are complementary, representing sequential phases of the policy-making process. The multiple stream model represents the topical discussion, lobbying and proposing that takes place on an ongoing basis. Once a policy window appears, i.e. a problem has been defined, a solution has been identified and the political conditions are right, the policy decision-making cycle comes into effect. The combined model recognises that although decision-makers 
may or may not play a role in the problem stream and policy stream during phase 1 , they must be involved in order for a policy window to appear and phase 2 to come into effect. To facilitate online democratic engagement, the Puzzled by Policy Platform ${ }^{1}$ was developed supported on this inform-consult-empower framework. This platform consists of three components, which have initially been designed around immigration policy, but can be applied to any policy domain. The Policy Profiler is a Web based tool which gives users the opportunity to find out about their preferences within the policy field of immigration. Furthermore, it allows users to compare their positions to the existing policy framework. U-debate is a multilingual, pan-European deliberation forum where users can view, discuss and share ideas on immigration policy. The goal of U-debate is to create consultation reports on policy topics, relating to draft policies or topics of public concern at local, national or EU level. In particular, the Puzzled by Policy U-debate tool is focused on the use of a deliberation model. The Widget enables the viral distribution of the Puzzled by Policy Platform throughout the Web, as the Widget can be embedded, and thus accessed, on any website, blog or social media site on the Internet.

\section{Multidimensional Engagement Approach}

Section 2 described the main challenges of incorporating citizen engagement into eparticipation initiatives. This section lays out a 13-dimension engagement approach that harnesses innovative technologies in cross-border and multilevel democratic decision-making. Although research and evidence have shown that there is no "onesize-fits-all" solution to involve citizens in policy making, there are essential dimensions that should be addressed in order to design a successful approach. The engagement approach presented in this paper is supported by an inform-consultempower framework developed in earlier work [8, 12], developed in consultation with academics and experts on e-participation, and based on a review of several existing frameworks that have been created around the world $[5,9,11,15]$ in order to address the following requirements of e-participation initiatives [16]: how to attract and sustain citizen participation, how to foster public involvement, how to promote deliberative democracy, and how to induce collaborative government. We found that to maximize the impact of e-participation programmes, these are the main elements that have to be defined when planning the pilot trials that use ICT:

1. Purposes and objectives: before launching an e-participation initiative, it is critical: to decide to what extent you are committed to taking public opinion into account in your decision making and to communicate clearly the nature of that commitment. The objectives have to be concrete, realistic, engaging and effective. As a consequence, it is essential to ensure the trust in the quality of what the public can contribute to the policy-making process.

2. Strategy: implementing real-world settings for active citizen engagement requires a detailed operation and dissemination plan. Operation strategy encompasses the

\footnotetext{
${ }^{1}$ http://join.puzzledbypolicy.eu/
} 
definition of topics and policy processes, identification of target groups and stakeholders, developing, testing and launching online tools, management and, facilitation. The dissemination plan addresses the dissemination strategy and channels for strategic promotion and marketing to engage users.

3. Process set up: setting up an e-participation initiative consists of defining a communication space where interactions among participants are taking place and content is produced and shared. It is not necessarily limited to policy-making and can also focus on societal participation or community building. E-participation initiatives present their main communication space through the use of online tools and can be extended by face-to-face communication and online social media. In order to establish a trustworthy and efficient communication space, it is essential to define communication norms that enable participants to engage into civilized interaction.

4. Management: Management of ICTs in cross-border and multilevel democraticdecision-making includes the following key elements: coordinating implementation activities, monitoring overall performance, ensuring goals and success criteria are met, managing risks and administering leads.

5. Topic selection: topic selection encompasses aspects like setting up a contextual framework for the information and the consultation level of participation. The main goal of topic selection is background information published on policy issues including data on policy developments, legislation, stakeholders' positions, public opinion, historical and institutional framework. As this content is usually very complex and information rich, topic presentation has to be extracted in an engaging and meaningful way for participants to read and understand.

6. Target group identification: the overall performance of an e-participation initiative in democratic decision-making and engaging participants depends on the adequate identification and involvement of target groups and stakeholders. There are three major target groups of potential users in selected policy field or public affairs: (1) decision-makers (government officials and politicians), (2) civil society professionals and volunteers (academia, experts, non-governmental organizations, media, labour unions, enterprises, informal groups, individual citizens) and (3) every-day-citizens: practising active citizenship. Any successful engagement approach design requires trade-offs between the intensity of small groups and the representativeness of larger samples. Local voluntary groups as leader groups are crucial to creating awareness and drawing average citizens into dialogue about their communities. These groups can act as intermediaries between the individual and decision-makers.

7. Time frame: planning time frames is essential to engage target audiences in a successful way. It is related to initiative duration and relevance. The impact of using ICTs for democratic decision-making is often depending on whether a topic or an issue addressed is currently on the political, public or media agenda. Therefore, e-participation initiative operation duration has to correlate to relevant public or political processes (e.g. public consultations), events (e.g. elections) and developments (e.g. economic crisis). Relevance time frames can be different in duration, comparing to operation time frames. As a consequence, participation initiatives have to be flexible by following up with developments in the field and respond to them, when there is an opportunity to influence policy-making. 
8. ICT tools: combining different online tools can help reducing the complexity of decision making. Tools developed should be designed in order to support different levels of participation when an inform-consult-empower framework is used [5, 8, 12], as well as, to address the needs and characteristics of diverse target groups. ICT tools design should combine elements of user-friendliness, visual appeals, and simplicity. A web site encompassing ICT tools selection by providing additional information about the initiative, community, developments, and results helps foster public involvement. Social media profiles and viral distribution can also facilitate community building. Allowing participants to co-design ICT tools can help involve them in the actual use of these tools.

9. Facilitation and support for deliberative democracy: facilitation is required when an e-participation initiative features interactive online and offline discussions and consultations, aiming to deliver policy related content. On the other hand, hardto-reach target groups (less educated, elderly, etc.) sometimes do not have adequate know-how or resources to fully benefit from the online tools available. Therefore, providing support channels for user inclusion is required. Moreover, the use of social deliberative skills is also essential for a successful facilitation. These skills refer to the abilities that participants need in order to work toward mutual understanding, mutual regard, and trust in deliberations in which participants start with heterogeneous goals, assumptions, values, or world-views. A non-active use of social deliberative skills lead to several inefficiencies: (1) some comments do not mesh with the topic to be discussed, and (2) use of the platform to discuss personal stories rather than the ideas presented. On the other hand, the use of negative language based on problems and criticism invites participants to focus on the negative aspects of individuals or communities, triggering defensiveness and as a result, tends to discredit or belittle [13]. The use of social deliberative approaches conceived to foster a collaborative construction of reality based on a systematic search for what works best is a key way to achieve a positive community and deliberative response [14].

10. Dissemination and involvement: regular and intensive dissemination is fundamental to create public visibility of the project. Dissemination should cover the online platform and its tools, share results, raise awareness in general, and also reach out to specific target groups. In general, a two-step planning is necessary to reach public visibility. The first step consists of identifying generic (mass media, $\mathrm{TV}$, press, radio, etc.) and specific (web sites, blogs, social media, networks, etc.) dissemination channels related to the policy issue, as well as creating new channels for the initiative (web site, e-mail, Facebook, Twitter, LinkedIn, Flickr and YouTube profiles). The second step focuses on creating professional and consistent dissemination materials (brand/logo, posters, web banners, bookmarks, initiative brochure and video presentation), which present key messages (teasers). Dissemination activities should include viral marketing, e-mailing, phone calls, newsletters and press releases, meetings, interviews, discussions, demonstrations, focus groups, workshops for target groups, conferences, online articles, and also participating at events related to the policy-issue of the participation initiative.

11. Feedback and impact: the first step to induce collaborative governance and successful engagement is a strong commitment to receive decision-makers' feedback and to create an impact analysis. Feedback and impact provide concrete 
evidence on how target groups' and stakeholders' input (e.g. citizen's opinions and positions) is considered by decision-makers, and how it is influencing policymaking (empower level of participation). At the same time, it generates trust in political institutions due to transparency of the process, as well perceiving participation initiatives as a viable tool for contributing to better decision-making.

12. Monitoring and evaluation: in essence, evaluation is the process of bringing all the e-participation initiative's results together to determine project success, impact achieved, lessons learned and to propose further recommendations and best practice. Statistical and qualitative information should be monitored on regular basis to keep on track with platform operation and to undertake timely actions for addressing potential risks. Evaluation serves several purposes such as: (1) to evaluate the results of the initiative; (2) to assess usefulness to citizens and decision makers, (3) to identify best practices; and (4) to provide further technical refinement suggestions, particularly with regard to accessibility and sustainability, and recommendations for correctly using the platform.

13. Sustainability: it is important to ensure that initiative results are available for an easy and cost-effective replication by potential adopters. A lot of e-participation trials in Europe are facing sustainability issues, therefore it is important to ensure that the technical solutions developed, as well as the experience and knowledge generated, will be utilized and sustained after the official project lifecycle has ended. The development of sustainability toolkits material is essential to enable potential adopters to explore the benefits of the participation initiative.

\section{Evidence to Date}

Puzzled by Policy kicked off in October 2010 with the aim of engaging citizens in the policy-making process. It was piloted in real-world settings across Greece, Hungary, Italy, and Spain. The purpose of the pilots was to engage key national and EU stakeholders into the e-participation process, covering immigration-policy issues by providing information, content management, process facilitation and promotion of the Puzzled by Policy platform, and to deliver policy proposals for targeted decisionmakers and institutions. A feedback mechanism for delivering results to the key decision makers via the tool and/or report was established, so recommendations could be made on how to shape/implement the immigration proposals that provide the most positive policy impacts to all involved. The use of the multidimensional approach described in section 4 resulted in significant engagement and the Puzzled by Policy platform proved very successful during 15 months of pilot operation, with 212,700 page views and 17,000 unique visitors. Over 6,800 people actively participated on the pilots, meaning that they at least completed the Policy Profiler quiz. In relation to the involvement of stakeholders, more than 100 NGOs were involved and over ten policy-makers at local, regional, and national levels. More than 1300 contributions were published in 118 u-debate discussions threads by 600 users. Eight informal and six formal feedbacks have been received from decision-makers. Table 1 summarizes the key points of this multidimensional approach in Puzzled by Policy project. 
Table 1: Summary of key dimensions and outcomes in the Puzzled by Policy project

\begin{tabular}{|c|c|}
\hline Dimensions & Outcomes \\
\hline $\begin{array}{l}\text { Purposes and } \\
\text { objectives }\end{array}$ & $\begin{array}{l}\text { Focus on irregular immigration to support social care services in Greece. Identification of } \\
\text { immigration and emigration issues by users, policy makers and NGOs in Hungary. } \\
\text { Discussing key policy topics on local election entitlement to vote, citizenship, and } \\
\text { qualification and professionalism acknowledgement in Italy. And, strengthening social } \\
\text { participation to incite urban dwellers and decision makers to participate in shaping } \\
\text { migration policies in Spain. }\end{array}$ \\
\hline Strategy & $\begin{array}{l}\text { All pilot countries were a great example of grass-roots, bottom-up citizens' discussions } \\
\text { that blend online and face-to-face activities to shape immigration issues and topics. }\end{array}$ \\
\hline Process set up & $\begin{array}{l}\text { Focus on policy-making, societal participation, and community building. Multilingualism } \\
\text { was enabled by offering the platform interface in the four pilot languages besides English, } \\
\text { and by an automatic translation tool to make user generated debate content accessible in all } \\
\text { major languages. }\end{array}$ \\
\hline Management & $\begin{array}{l}\text { Constant and flexible management by pilots. Creation of feedback channels with decision- } \\
\text { makers. }\end{array}$ \\
\hline $\begin{array}{l}\text { Topics } \\
\text { selection }\end{array}$ & $\begin{array}{l}14 \text { topic statements were identified in the fields of immigration for employment purposes, } \\
\text { immigration for studying purposes, immigration for reasons of family reunification, long- } \\
\text { term resident immigration, and irregular immigration. Enabling bottom-up identification of } \\
\text { topics by NGOs, advocacy groups and individuals was further strengthening inclusiveness } \\
\text { of the process, and motivating decision-makers, stakeholders and participants to recognize } \\
\text { and use Puzzled by Policy online platform as a relevant channel for participation. }\end{array}$ \\
\hline Target groups & $\begin{array}{l}\text { Hard-to-reach group of pilot trials was defined as being under-represented in immigration } \\
\text { policy-making due to limited access and knowledge about decision-making, or due to low } \\
\text { level of ICTs skills. This group was composed of immigrant, young, elderly, less educated } \\
\text { and unemployed people. }\end{array}$ \\
\hline Time frame & $\begin{array}{l}\text { Pilot countries were flexible by following with up-to-date developments and responsive to } \\
\text { act, when there was an opportunity to influence policy-making in terms of adopting 'hot' } \\
\text { topics. }\end{array}$ \\
\hline ICT tools & $\begin{array}{l}\text { The web site www.puzzledbypolicy was encompassing ICT tools selection by providing } \\
\text { additional information about the project, community, developments and results. }\end{array}$ \\
\hline $\begin{array}{l}\text { Deliberative } \\
\text { democracy }\end{array}$ & $\begin{array}{l}\text { An appreciative inquiry model [13] was explored and applied by the Spanish pilot in order } \\
\text { to foster and vitalize the active engagement of the different actors involved in online and } \\
\text { offline debates. The use of this approach has shown that it was the questions designed } \\
\text { from an appreciative approach that yielded the most visits and comments }\end{array}$ \\
\hline Dissemination & $\begin{array}{l}\text { Multichannel and multilingual dissemination at the national and the EU level was } \\
\text { supported by a news agency partner. Face-to-face dissemination and looking for synergies } \\
\text { with immigration mediators in the field, who had already established communication } \\
\text { channels, provided additional visibility for pilot countries. }\end{array}$ \\
\hline Feedback & $\begin{array}{l}\text { Official feedbacks received from decision-makers were disseminated through pilot } \\
\text { countries' dissemination channels, and a special sub-page was established within the } \\
\text { platform that provided access to pilot countries' consultation reports and feedbacks } \\
\text { received from decision-makers, to induce collaborative governance on how to } \\
\text { shape/implement the immigration proposals that provide the most beneficial policy } \\
\text { impacts to all involved. }\end{array}$ \\
\hline $\begin{array}{l}\text { Monitoring and } \\
\text { evaluation }\end{array}$ & $\begin{array}{l}\text { A five-pillar framework was used to evaluate the project. These pillars were: evaluation } \\
\text { metrics, evaluation stakeholders, evaluation instruments, and data collection tools and data } \\
\text { analysis tools. An impact analysis was performed by developing an impact table referring } \\
\text { to each level of the inform-consult-empower framework, and an analytical framework } \\
\text { referring to different components such as: external factors, resources, operational results, } \\
\text { and quantitative, qualitative, political, societal and cultural outcomes. }\end{array}$ \\
\hline Sustainability & $\begin{array}{l}\text { A sustainability toolkit was developed to enable potential adopters to explore the benefits } \\
\text { of Puzzled by Policy, hosted by a standalone web site } \\
\text { (http://puzzledbypolicy.moonfruit.com/). }\end{array}$ \\
\hline
\end{tabular}




\section{Lessons Learned}

Addressing public engagement is a critical challenge for the design, development, and implementation policy in the $21^{\text {st }}$ century. Reaching out to target groups requires huge effort, commitment, and funding. In addition to the costs of suitable technology, these e-participation projects require careful planning and consistent facilitation and moderation. Through the implementation of the aforementioned dimensions, we have drawn key lessons learned from the Puzzled by Policy pilots. These can be summarized as:

1. The initiative owner should embrace users and have a user-centric attitude: Users' needs and expectations from tangible (platform and tools) and intangible (the participatory process) aspects should be taken under consideration throughout the initiative. Engaging citizens in policy-making is not a means for diminishing representation, but for strengthening it. Identification of relevant topics should be implemented in bottom-up collaboration with target (interest) groups, experts, and decision-makers. Complex topics need to be presented in a simple yet relevant way aided by starting questions, data visualisations, or scenario building, enabling participants to provide different kinds of inputs (opinions, proposals, arguments, etc.). Sensitive topics should be addressed by mediators in the policy field and by allowing anonymous participation supported by active facilitation. However, anonymity provides room for inappropriate comments and insults, while identification typically leads to a more constructive conversation online.

2. Partnership with mediators in the policy field: Top down oriented projects are facing difficulties in engaging target groups in participatory processes. Project partnership in topics identification, e-participation initiative operation and influencing decision-makers with mediators in the policy field such as civil society organisations, non-governmental organisations, public services and informal groups can increase participation of individuals and communities otherwise not involved in the process. Also, mediators are often acting as stakeholders in the field, actively promoting and increasing participation of target groups via their communication channels and transferring knowledge, experience and feedback. For that purpose, it is essential to network and establish trust with mediators in the policy field. As a result, the bottom-up approach is often more suitable when aiming at a critical mass of participating citizens or when the agenda is not predetermined.

3. Multichannel involvement and wide, consistent dissemination is necessary to raise awareness: Combining advantages of face-to-face group events and the web can result in simultaneous engagement of dispersed groups as well as hard-to-reach individuals having different communication needs and styles. It is also important to maintain a steady dissemination of regular updates on and progress of the participatory process. On the other hand, intensive dissemination campaign such as project or platform launch with a 'bang', are crucial for obtaining an initial visibility of the process. Dissemination content and tool needs to be visually attractive and user friendly. It is very difficult and demanding to build up a sustainable community of stakeholders around a top-down oriented initiative with a limited time span. Alternatively, it is worth considering a participatory design 
approach, enabling target groups to identify or even create their own channels of involvement and dissemination suitable to their needs.

4. Policy content production: High-quality content produced and shaped in a vibrant, multi-stakeholder, open, and trustworthy space and supported by ICT is presenting one of the main foci of smart governance. Generating relevant policy knowledge and information in a structured, detailed and proposal oriented format supported by arguments and evidence, is providing a valuable decision-making resource in addition to the regular public opinion polls. On the other hand, highquality content provided by an informed and consulted public is enabling policymakers to make decisions based on relevant and useful information as well as motivating them to participate in the process by providing feedback. Finally, highquality policy content is attracting the attention of mass media interested to report on publicly relevant topics.

5. Process management and facilitation: The primary purpose of e-participation management is to enable a successful and transparent implementation of the participatory process. Therefore, well defined goals and expected results (e.g. what will happen with citizen input) are set up in an e-participation implementation plan and a dissemination/involvement plan. Management must also include monitoring the progress and assessing the results/impact of the process (e.g. informed citizens, improved dialogue, and better legislation). Management efforts pursue the sustainability of participatory processes. As a result, adequate organisational and administrative capacity is fundamental when enabling citizen involvement in multilevel and cross-border governance. On the other hand, a primary goal of eparticipation facilitation is to establish mutual trust among stakeholders involved and to contribute to the legitimacy of the process. Facilitation is about uncovering hidden agendas and securing equal and unbiased conditions for participation of stakeholders by providing support and guidance. Efforts may include a more or less pro-active mediation (or migration) of views expressed elsewhere, either manually or by using semantic technologies, e.g. by carefully analysing and reposting the core of messages found in social media, in a way that matches the context and structure of the actual consultation. Facilitation is further strengthening transparency of the process by increasing visibility of contributions, creating publicly available summary reports, as well as publishing feedback from decisionmakers. In other words, facilitation is bridging easy-to-add contributions and easyto-absorb summaries Rules of facilitation need to be public. Another key aspect of facilitation is to motivate stakeholders to actively participate in the process and to provide solutions, when there is a stalemate in the process due to conflict.

6. Decision-maker involvement: Politicians, political parties and government institutions at national and EU level are facing low levels of legitimacy and trust due to quick, unsuccessful, and often unpopular decision-making targeting the social and economic crisis in Europe. As a result, citizens are often not motivated to collaborate with elected officials. Still, it is crucial to identify and engage trustworthy/accountable politicians to act as stakeholders of participatory projects. An active campaign to engage decision makers in the process of consultation with citizens is needed. Politicians involved need to be active in policy topics which are subject of participatory projects, and they need to have adequate capacities to provide their own input/feedback. Usually, local decision-makers are more flexible 
to obtain the commitment and involvement of political representatives in order to take into account the proposals which have been built together with stakeholders.

7. Feedback and impact: Receiving decision-makers' formal or informal feedback to pilot' reports (results) during or after the involvement process enables participants and other stakeholders to assess their impact on decision-making. Feedbacks also reflect the actual degree of institutionalized empowerment and relevance of the process. In order to provide feedback, government institutions and politicians have to be informed about topics and engaged in the process from the beginning. For that purpose, facilitator's reports and conclusions deriving from participants' contributions have to be well structured, meaningful and concrete. Since public participation is demanding in terms of time and resources, participants have to be well informed about the impact of involvement and have to have an opportunity to assess how they are benefiting from the process. As a result, actual empowerment is not only political but also societal in nature (e.g. participatory culture, improved communication, community building). Therefore it is very important that decisionmakers' feedback and impact evidence are made as public as possible through various dissemination channels in order to induce a collaborative governance.

\section{Conclusions}

Puzzled by Policy has been an innovative and influential project, pushing boundaries of online citizen engagement on key policy-topics. It has proven to be an adaptive and integrated approach to e-participation, which has set new benchmarks for online participation in the future. Puzzled by Policy uses a multidimensional engagement approach, supported by an inform-consult-empower framework. To maximise the impact of the e-participation process, we defined 13 key dimensions for that have to be defined when planning pilot trials for the purpose of using ICT in cross-border and multilevel democratic decision-making. Puzzled by Policy pilot trials were implemented according to these step-by-step planning, development, implementation, and operation dimensions, which in turn enabled us to extract key lessons learned. The importance of inclusiveness, communication and multichannel were all highlighted in our findings. The results of Puzzled by Policy are embedded in each of the four pilot sites, disseminated throughout the communities and organizations who have now come to expect engagement on policy matters with the official representatives. The Puzzled by Policy approach and platform will be applied to new initiatives, policy-areas and jurisdictions to enable future engagement of citizens on critical policy topics.

\section{Acknowledgements}

The work presented in this paper has been funded by the European Union under Grant $\mathrm{N}^{\circ} 256261$ (Puzzled by Policy - CIP-ICT-PSP-2009-3bis), in part by a research grant from Science Foundation Ireland (SFI) under Grant Number SFI/12/RC/2289", and in part by the Spanish Government under the project TIN2011-24598. 


\section{References}

[1] Europe's Information Society Thematic Portal. http://ec.europa.eu/information_society/activities/ict_psp/participating/calls/call_proposals_09_ bis/index_en.htm

[2] P. Prieto-Martín, Luis de Marcos, J. Martínez. "The e-(R)evolution will not be funded”. In European Journal of ePractice vol. 15: Policy lessons from a decade of eGovernment, eHealth \& eInclusion, 2012.

[3] S. Smith.D1.3c: "Main benefits of eParticipation developments in the EU a contextualisation with reference to the EU governance regime and the European public sphere", Study and supply of services on the development of eParticipation in the EU, ed. European eParticipation, 2009.

[4] European eParticipation Summary Report, 2009. http://ec.europa.eu/information_society/activities/egovernment/docs/reports/eu_eparticipation_ summary_nov_09.pdf

[5] Ann Macintosh. "Characterizing E-Participation in Policy-Making”, HICSS 37 $7^{\text {th }}, 2004$.

[6] OECD. "Promises and problems of e-democracy; Challenges of Citizen on-line Engagement", 2003.

[7] L. Porwol, A. Ojo, J. Breslin. "Harnessing the duality of e-Participation - Social Software Infraestructure Design”, In ICEGOV 2013.

[8] D. Lee, N. Loutas,., E. Sánchez-Nielsen,.E. Mogulkoc, \& Lacigova. "Inform-consultempower: a three-tiered approach to eParticipation." International Electronic Participation Conference ePart 2011. LNCS 6847, pp 121-132, Springer Berlin Heidelberg.

[9] Vicent Price. "Citizens Deliberation Online: Theory and Some Evidence". In Online Deliberation: Design, Research, and Practice, 2009, CSLI Publications, Todd Davies and Seeta Peña G. (eds.) pp.37-58.

[10] OECD. "Focus on Citizens: Public Engagement for Better Policy and Services", OECD Studies on Public Engagement, 2009.

[11] Kingdon, "Agendas, Alternatives and Public Policies". Addison-Wesley Publishers, 1984.

[12] E. Sánchez-Nielsen, \& D. Lee. "eParticipation in Practice in Europe: The Case of" Puzzled by Policy: Helping You Be Part of EU." $46^{\text {th }}$ International Conference on System Sciences (HICSS 2013), pp. 1870-1879, Hawaii, EEUU.

[13] K. Gergen,. “An invitation to social construction”. London: SAGE Publications.

[14] E. Sánchez-Nielsen \& C. Martín-Váquez. "Exploring how the appreciative inquiry model can vitalize the online citizen debate". $13^{\text {th }}$ European Conference on e-Government, pp. 424431 Como, Italy, 2013.

[15] S. Bittle, C. Haller, A. Kadlec. "Promising practices in online engagement". Center for Avances in Public Engagement, 2009.

[16] Center for Intedisciplinary Law and Policy Studies of the Ohio State University. "Building democracy through online citizen deliberation: a framework for action", Peter M. Shane (ed.), 2008.

[17] Conference of International NGO at the Council of Europe 2009. "Code of good practice for civil participation in the decision-making process", 2009. 